\title{
Flow cytometric DNA hypertetraploidy is associated with unfavourable prognostic features in breast cancer
}

\author{
António E Pinto, Saudade André, Mafalda Nogueira, Evelina Mendonça, Jorge Soares
}

\begin{abstract}
Aim-Breast tumours with a DNA content higher than $4 \mathrm{~N}$ (hypertetraploidy) are not well characterised. The aim of this study was to evaluate the clinical and biological characteristics of 51 hypertetraploid breast carcinomas selected from a series of 860 consecutive cases analysed by flow cytometry.

Methods-The clinicopathological characteristics of the hypertetraploid group were compared with those of a control group of 138 non-hypertetraploid breast carcinomas. Breast tumours from patients submitted to surgery as primary therapeutic approach (15 hypertetraploid and the 138 non-hypertetraploid) were TNM staged and classified according to the histological type and grade. The remaining 36 patients had advanced neoplastic disease at presentation and were classified by cytological criteria only. DNA flow cytometric analysis was performed on fresh-frozen samples stained with propidium iodide. Hormone receptors were analysed by immunocytochemistry.
\end{abstract}

Results-The incidence of hypertetraploid breast tumours was $5.9 \%$ (51 of 860$)$. All the patients were women and the mean age at diagnosis was 65 years. There was a family history of breast cancer in $21.6 \%$ of cases. In the group of operated patients, $33.3 \%$ had pT3 tumours and $53.3 \%$ had axillary lymph node metastases. All but one tumour were invasive ductal carcinomas; the remaining was an invasive papillary carcinoma. Ten $(66.7 \%)$ tumours were classified as poorly differentiated carcinomas. Oestrogen and progesterone receptors were negative in $33(64.7 \%)$ and $38(74.5 \%)$ tumours, respectively. At last follow up, $35(72.9 \%)$ patients were alive, while $13(27.1 \%)$ died of disease within three years of diagnosis. Statistical comparison of the clinicopathological features of hypertetraploid $v$ non-hypertetraploid breast carcinomas yielded a significant difference in tumour size $(p<0.001)$, histological grade $(p<0.001)$, hormone receptor status $(p<0.001)$, and overall survival $(p<0.001)$ between the two groups.

Conclusion-Flow cytometric DNA hypertetraploidy is related to clinicopatho- logical features of breast cancer usually associated with unfavourable prognosis. (F Clin Pathol 1997;50:591-595)

Keywords: DNA hypertetraploidy; flow cytometry; breast carcinoma; prognostic features

Axillary nodal status is generally accepted as the most valuable predictor in assessing the risk for recurrence and metastatic disease in breast cancer. ${ }^{1-4}$ Nevertheless, the heterogeneous clinical course of the disease emphasises the need for additional prognostic markers that might improve the identification of patients with unfavourable clinical outcome..$^{5-8}$

Nuclear DNA ploidy has been widely evaluated for its potential prognostic significance in a variety of human neoplasms ${ }^{9}{ }^{10}$; however, in breast cancer, flow cytometric data that correlate the DNA content with the clinical behaviour of the tumours are conflicting, in part because of the lack of standardisation of tissue sample preparation and cell cycle analysis. ${ }^{10}$ Some investigations have suggested the independent prognostic value of DNA ploidy, ${ }^{11-14}$ while others have failed to do so. ${ }^{15-18}$ Several studies have also shown that the subdivision of DNA aneuploid tumours according to DNA index improves the discrimination of prognostically distinct groups of patients. ${ }^{19-22}$ The clinical and biological significance of breast tumours with a DNA content higher than $4 \mathrm{~N}$ (hypertetraploidy) is not well characterised.

The purpose of this study was to evaluate the clinical and histopathological characteristics of a series of 51 consecutive breast carcinomas classified as hypertetraploid using DNA flow cytometric criteria and to correlate them with short term follow up.

\section{Methods}

CLINICOPATHOLOGICAL DATA

One hundred and eighty nine patients (all women) with breast carcinomas were selected from a series of 860 consecutive cases analysed by flow cytometry at the Instituto Português Oncologia in Lisbon Centre, Portugal between 1990 and 1995. Two distinct groups of tumours based on flow cytometric DNA index criteria were evaluated: one group comprised 51 hypertetraploid breast carcinomas and the other 138 non-hypertetraploid tumours. All the patients in the latter group and 15 in the former underwent surgery as the primary therapeutic approach. The remaining 36 with 


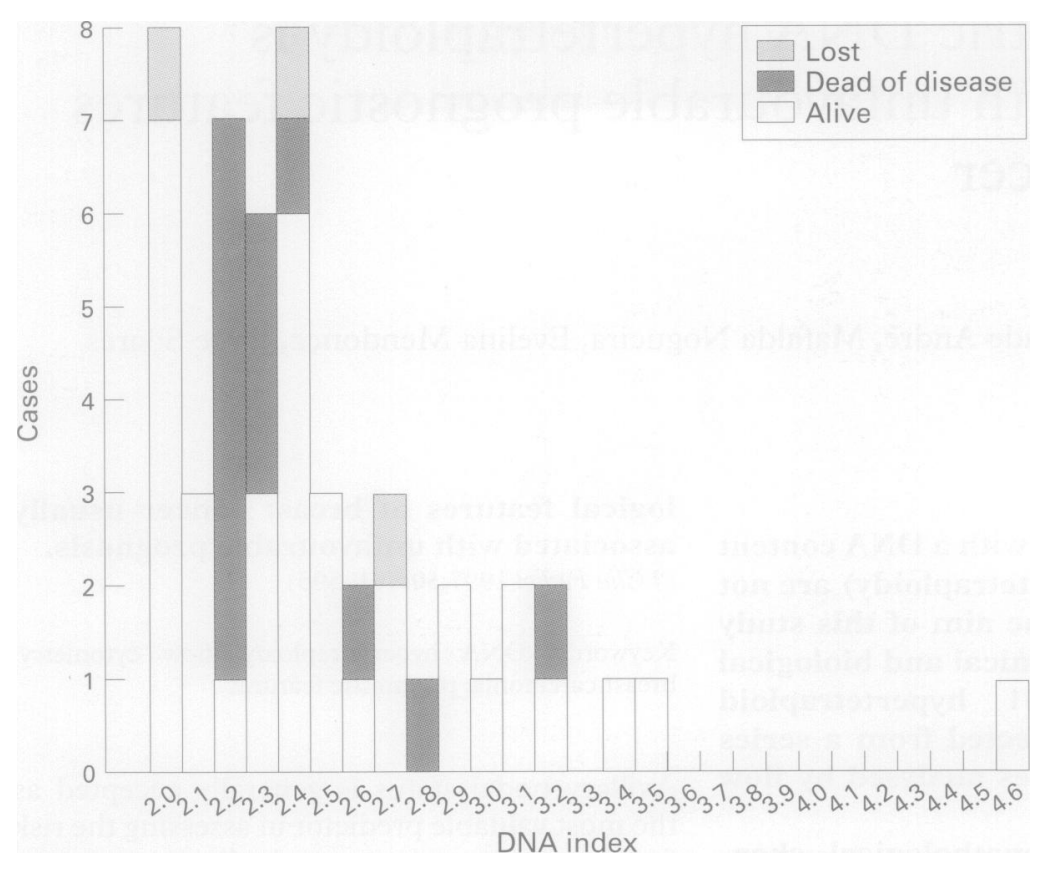

Figure 1 Frequency distribution of the DNA index of 51 hypertetraploid breast carcinomas. Ten of 13 patients who died of the disease had a DNA index of between 2.20 and 2.50. Three cases were lost to follow up.

hypertetraploid breast tumours had advanced neoplastic disease at presentation and were treated with local radiation or chemotherapy or both. In these patients, flow cytometry was performed on fine needle aspirates before treatment.

All the surgically resected carcinomas were histologically reviewed and classified according to tumour size (T) and lymph node status $(\mathrm{N})$ (UICC TNM staging system, 1992), ${ }^{23}$ histological type (WHO classification, 1982), ${ }^{24}$ and histological grade (Elston and Ellis criteria, 1991) ${ }^{25}$ The 36 unoperable neoplasms were classified by cytological criteria. ${ }^{26}$ The patients' ages, family history of breast cancer, and follow up information were retrieved from clinical charts.

Table 1 Clinical and histopathological characteristics of the hypertetraploid and the non-hypertetraploid groups of breast cancer

\begin{tabular}{|c|c|c|c|c|c|}
\hline & \multicolumn{2}{|c|}{ Hypertetraploid } & \multicolumn{2}{|c|}{ Non-hypertetraploid } & \multirow[b]{2}{*}{ p value } \\
\hline & Number & $\%$ & Number & $\%$ & \\
\hline Family history & & & & & NS \\
\hline No & 40 & 78.4 & 119 & 86.2 & \\
\hline Yes & 11 & 21.6 & 19 & 13.8 & \\
\hline Tumour size & & & & & $<0.001$ \\
\hline $\mathrm{T} 1$ & 3 & 20.0 & 50 & 36.2 & \\
\hline $\mathrm{T} 2$ & 7 & 46.7 & 82 & 59.4 & \\
\hline T3 & 5 & 33.3 & 6 & 4.4 & \\
\hline Nodal status & & & & & NS \\
\hline Negative & 7 & 46.7 & 71 & 51.4 & \\
\hline Positive & 8 & 53.3 & 67 & 48.6 & \\
\hline Histological grade & & & & & $<0.001$ \\
\hline G1 & - & - & 39 & 28.3 & \\
\hline G2 & 5 & 33.3 & 68 & 49.2 & \\
\hline G3 & 10 & 66.7 & 31 & 22.5 & \\
\hline Oestrogen receptor & & & & & $<0.001$ \\
\hline Negative & 33 & 64.7 & 8 & 17.4 & \\
\hline Positive & 18 & 35.3 & 38 & 82.6 & \\
\hline Progesterone receptor & & & & & $<0.001$ \\
\hline Negative & 38 & 74.5 & 17 & 37.0 & \\
\hline Positive & 13 & 25.5 & 29 & 63.0 & \\
\hline Follow up & & & & & $<0.001$ \\
\hline Alive & 35 & 72.9 & 136 & 98.5 & \\
\hline Dead of disease & 13 & 27.1 & 2 & 1.5 & \\
\hline
\end{tabular}

HORMONE RECEPTOR EXPRESSION

Immunocytochemical analysis of oestrogen receptors (ER) and progesterone receptors (PR) was performed either on cytological smears, using the PAP technique ${ }^{27}$ (prediluted kits ER-ICA and PgR-ICA monoclonal; Abbott Laboratories, Chicago, Illinois, USA) or on paraffin wax embedded material using the streptavidin-biotin complex peroxidase technique $^{28}$ and the microwave antigen retrieval technique. ${ }^{29} \mathrm{ER}$ and $\mathrm{PR}$ immunostaining was done overnight at $3^{\circ} \mathrm{C}$ with monoclonal antibodies diluted 1/20 (Ref. 1344; Immunotech SA, Marseille, France) and 1/10 (PgRICA monoclonal; Abbott), respectively. The results were recorded as percentage of positively stained target cells-samples with more than $10 \%$ stained nuclei were deemed positive.

DNA FLOW CYTOMETRY STUDY

Flow cytometric analysis was performed either on frozen samples of specimens obtained at the time of surgery or on fresh material from fine needle aspirates. ${ }^{30}$ Tissue not processed immediately was stored at $-80^{\circ} \mathrm{C}$. The technical protocol was quite similar on both biological specimens, the only difference was that for fine needle aspirate samples the disaggregation step was not used. Briefly, the tissue samples were mechanically minced using scalpel blades and rinsed in cold phosphate buffered saline (PBS). The cell suspension obtained was counted with a haemocytometer and adjusted to a concentration of approximately $1 \times 10^{6}$ cells $/ \mathrm{ml}$. For DNA analysis, the nuclei were stained with propidium iodide $50 \mu \mathrm{g} / \mathrm{ml}$ in Tris $\mathrm{MgCl}_{2}$ buffer for one hour in the dark at room temperature, treated with RNase $1 \mathrm{mg} / \mathrm{ml}$ in PBS and $0.05 \%$ Nonidet P40. Immediately before the flow cytometric analysis the specimens were injected through a 27 gauge needle and then filtered through a $55 \mu \mathrm{m}$ nylon mesh. The stained nuclei were analysed on an Epics Profile II flow cytometer (Coulter Electronics, Hialeah, Florida, USA) equipped with a $488 \mathrm{~nm}$ argon ion laser. The flow cytometer was considered calibrated when coefficients of variation $<2.0 \%$ were obtained with fluorescent microspheres (DNA Check lot 5948 Coulter Corporation). Chicken red blood cells were used as internal standard to help the identification of the $G_{0} / G_{1}$ diploid population. ${ }^{31}$ At least 20000 nuclei were collected per run and recorded on a single parameter 256 channel integrated fluorescence histogram.

DNA HISTOGRAM INTERPRETATION

Cell cycle analysis of DNA histograms was performed using the Multicycle program (Phoenix Flow Systems, San Diego, California, USA), based on the mathematical model of Dean and Jett. ${ }^{32}$ DNA ploidy was expressed by the DNA index, which is the ratio of the mean channel number of the $G_{0} / G_{1}$ peak of the tumour cell population to that of the diploid reference peak. The reference cells used were mixed non-malignant diploid cells (lymphocytes, stromal cells, endothelial cells) from the same tumour sample analysed. Specimens were considered diploid if they had a single 


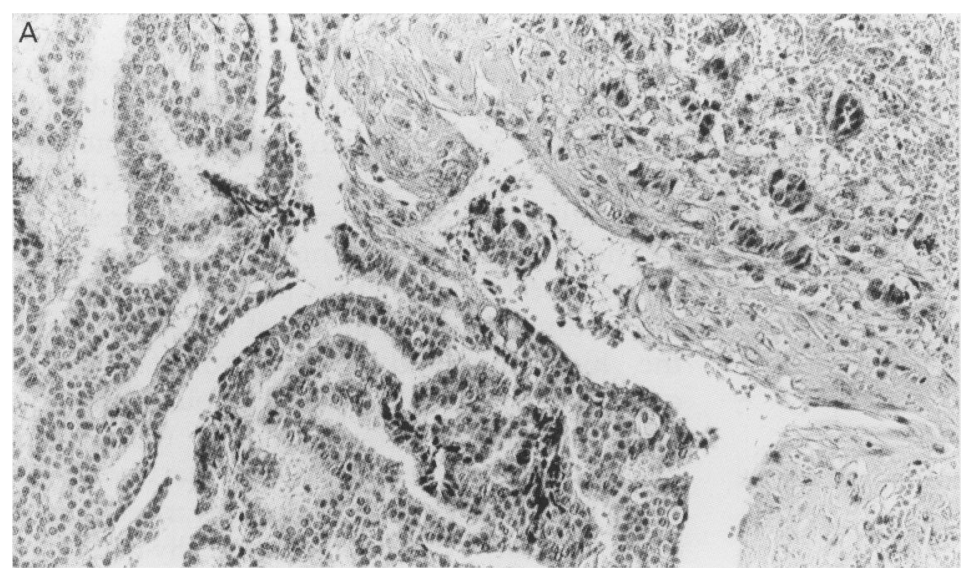

Figure 2 (A) pT1 invasive papillary carcinoma and (B) its representative hypertetraploid histogram with a DNA index of 2.20 .

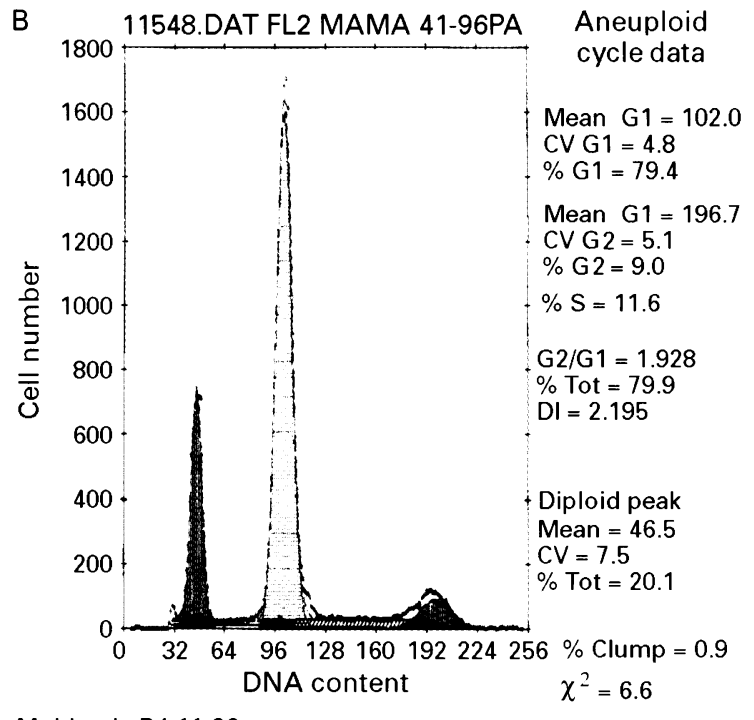

Multicycle D4-11-96

34609 cells \%debris: 6.1
$\mathrm{G}_{0} / \mathrm{G}_{1}$ peak, and as aneuploid when they exhibited at least two discrete peaks, with an abnormal $\mathrm{G}_{0} / \mathrm{G}_{1}$ peak containing a minimum of $20 \%$ of the total events and having a corresponding $\mathrm{G}_{2} \mathrm{M}$ peak. ${ }^{33}$ A more detailed subgrouping based on the DNA index estimates was used to classify the tumours: the DNA index range of the tetraploid region was based on the mean quotient of $\mathrm{G}_{2} \mathrm{M} / \mathrm{G}_{0} \mathrm{G}_{1}$ (mean channel units) for 100 consecutive diploid breast cancer samples and was found to be between 1.92 and 2.04. Consequently, all hypertetraploid tumours included in the present study had a DNA index greater than 2.04. Tumours that showed more than one abnormal population were classified as multiploid.

STATISTICAL ANALYSIS

Frequency tables were obtained for all the clinicopathological parameters evaluated. $\chi^{2}$ and Fisher's exact tests were used to define the correlation between clinical and biological characteristics of the two (hypertetraploid $v$ nonhypertetraploid) groups of tumours. $\mathrm{P}$ values $<0.05$ were considered significant.

\section{Results}

The overall incidence of hypertetraploid breast tumours was $5.9 \%$ ( 51 of 860 ). The frequency distribution of the respective DNA index ranged from 2.06 to 4.63 (fig 1). Seventeen cases were classified as multiploid as they had, together with the hypertetraploid clone, another aneuploid population. In the group of non-hypertetraploid breast carcinomas, 77 (55.8\%) tumours had a DNA diploid pattern and $61(44.2 \%)$ were DNA aneuploid.

The clinical and histopathological characteristics of the two groups (hypertetraploid $v$ nonhypertetraploid breast tumours) are shown in table 1 . In the hypertetraploid group the mean age at diagnosis was 65 years (range 40-88), $60 \%$ were older than 65 years. Eleven patients $(21.5 \%)$ had a family history of breast cancer. All but one tumour were classified as invasive ductal carcinomas; the remaining tumour was from a 59 year old patient alive at the end of the follow up period and was a pT1 invasive papillary carcinoma with axillary nodal involvement and a DNA index of 2.20 (fig 2). The distribution of the hypertetraploid cases according to the tumour size was as follows: $\mathrm{T} 1$, three cases $(20.0 \%)$; T2, seven cases $(46.7 \%)$; and T3, five cases $(33.3 \%)$. The mean number of axillary nodes removed in the 15 surgically treated patients was 10 . Axillary lymph node metastases were present in eight $(53.3 \%)$ patients.

From the 15 tumours available for histological grading, five $(33.3 \%)$ were classified as G2 (moderately differentiated) and $10(66.7 \%)$ as G3 (poorly differentiated).

Hormone receptor status was determined in the entire hypertetraploid cohort: oestrogen receptors (ER) and progesterone receptors (PR) were negative in $33(64.7 \%)$ and 38 $(74.5 \%)$ tumours, respectively.

Three patients were lost to follow up, in the others follow up ranged between six months and five years (median two years). At last follow up, $35(72.9 \%)$ patients were alive, four had distant metastases, and the other 31, including all patients who underwent mastectomy, had no evidence of recurrent disease. Thirteen patients $(27.1 \%)$ died within three years of diagnosis, 10 of whom (76.9\%) had a DNA index between 2.20 and 2.50 (fig 1 ).

In the non-hypertetraploid group of breast carcinomas, the mean age of the patients was 57 years (range 33-86 years) and 19 patients $(13.8 \%)$ had a family history of breast cancer. Fifty $(36.2 \%)$ tumours were classified as $\mathrm{T} 1$, $82(59.4 \%)$ as T2, and $6(4.4 \%)$ as T3. Nodal involvement was present in $67(48.6 \%)$ tumours. Thirty nine $(28.3 \%)$ breast carcinomas were considered as G1, $68(49.2 \%)$ as G2, and $31(22.5 \%)$ as G3. Hormone receptor analysis was performed in 46 breast tumours in this group, $8(17.4 \%)$ were ER negative and 17 (37.0\%) were PR negative. Only two patients $(1.5 \%)$ in this cohort died of the disease.

There was a statistically significant difference between the two groups in regard to tumour size, grade of differentiation, hormone receptor status, and overall survival 


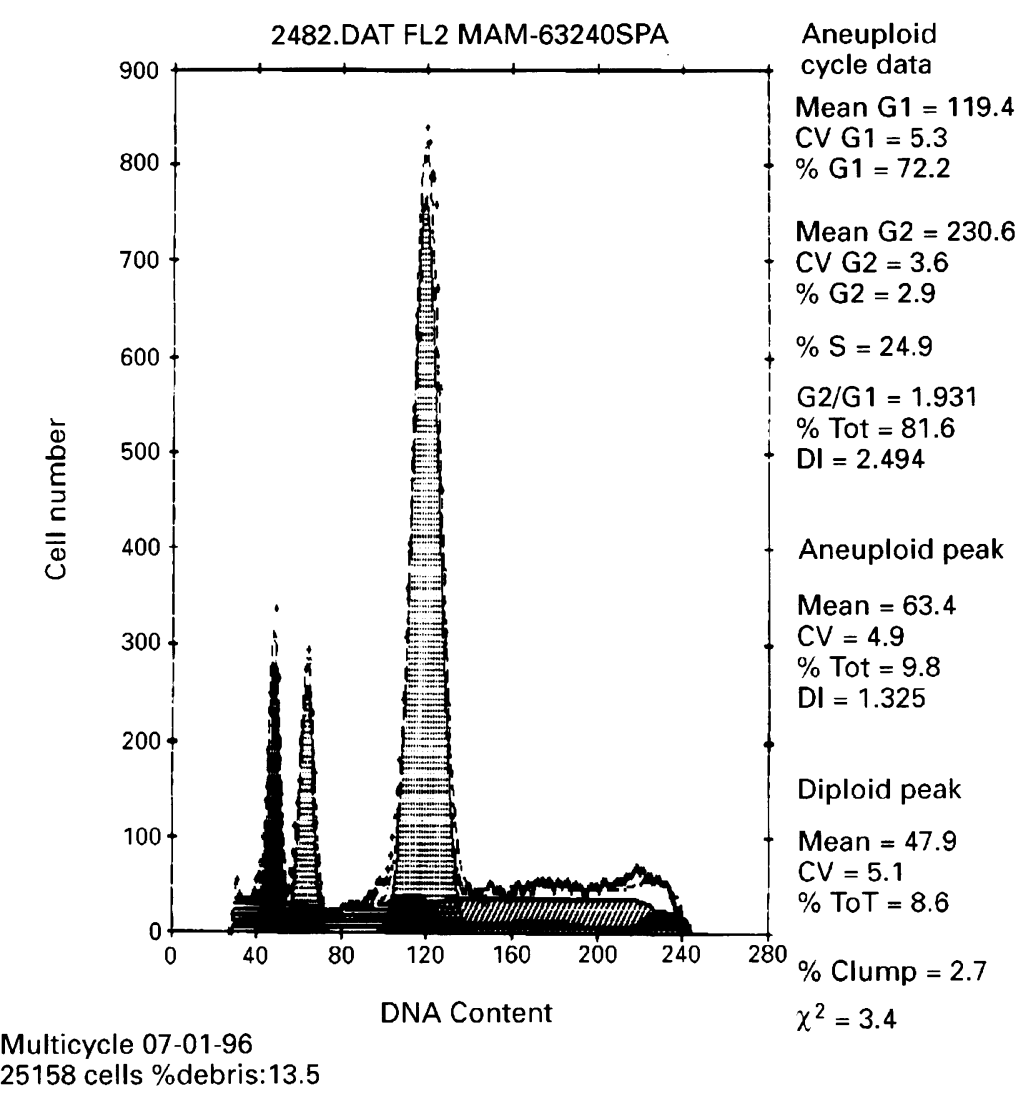

Figure 3 Representative histogram of a DNA multiploid tumour with an aneuploid population (DNA index 1.33) and a hypertetraploid clone (DNA index 2.49).

$(\mathrm{p}<0.001)$. There was no difference between the groups for family history of breast cancer and nodal status.

\section{Discussion}

Conventional flow cytometric classification of tumours into two categories, DNA diploid and DNA aneuploid, provides biological information that is not optimal in assessing the potential prognostic value of DNA ploidy. A recent consensus review of accumulated flow cytometric studies in breast cancer concluded that aneuploidy per se cannot be assumed as an independent prognostic factor, but the degree of DNA aneuploidy may have clinical relevance. ${ }^{10}$ Accordingly, some authors using DNA index classification criteria, claimed that DNA flow cytometry was useful for the identification of subgroups of patients presenting a higher probability of subsequent relapse. ${ }^{19-22}$ There is wide acceptance that hypertetraploid breast tumours have a poor clinical outcome, ${ }^{10} 212234$ however, this conclusion has scarce support, being largely based on theoretical documentation.

In our original series of 860 breast carcinomas, the incidence of hypertetraploid tumours was $5.9 \%$ ( 51 cases), similarly to data previously reported. ${ }^{810212235}$

Fisher et al analysed the relation between age and disease survival in node positive breast cancer patients, and defined a biphasic curve with higher degrees of risk among patients younger than 40 years and older than $65 .{ }^{36}$ All the patients of our hypertetraploid group were older than 40 and $60 \%$ of them were over 65 , which is in accordance with Toikkanen et al's statement that DNA aneuploidy with a high
DNA index is more frequent in elderly patients. ${ }^{37}$ In our series, family history of breast cancer was found in $21.6 \%$ of the cases, significantly higher than the percentage found in the group of non-hypertetraploid breast tumours $(13.8 \%)$, which was similar to the mean value $(15 \%)$ reported in the pertinent literature for the breast cancer population. ${ }^{\prime}$

There are still conflicting results with respect to the correlation of DNA ploidy with tumour size and nodal status in breast cancer. ${ }^{1138}{ }^{39}$ In the hypertetraploid group, $46.7 \%$ of the operated patients had pT2 tumours and one third presented tumours larger than $5 \mathrm{~cm}$ (pT3). It is noteworthy that all the remaining $36(70.6 \%)$ patients presented advanced stages of the disease. They characteristically had large tumours and surgery was not considered as primary treatment. The positive correlation between tumour size and DNA hypertetraploidy is in agreement with Sigurdsson et al who found a relation between large tumour size and the tendency for higher DNA aneuploid content and biological aggressiveness. ${ }^{\text {to }}$

The extent of nodal involvement is a well documented determinant of the overall breast cancer prognosis. ${ }^{14}$ Ottesen et al showed a statistically significant association between node positive tumours and DNA hypertetraploidy. ${ }^{41}$ In the present hypertetraploid group, we verified the presence of axillary lymph node metastases in slightly more than half of the operated cases. As discussed for the tumour size, the vast majority of the unoperable patients also had clinically and mammographically evident axillary node involvement.

In a review of 56 publications (10 323 invasive breast carcinomas), Frierson showed that DNA ploidy correlated strongly with the histological grade of the neoplasm. ${ }^{8}$ Despite the small sample size of our surgically treated cases, our study also found a prevalence of the poorly differentiated phenotype (66.7\%) among the hypertetraploid breast tumours.

Frierson emphasised that most studies showed no significant correlation between DNA aneuploidy and hormone receptor status. ${ }^{8}$ In contrast, and in agreement with previous studies that demonstrated a positive correlation between aneuploidy and loss of hormone receptor activity in breast cancer, ${ }^{35+2+3}$ our series of hypertetraploid breast tumours revealed a high incidence of negativity of ER (64.7\%) and PR (74.5\%).

The most striking feature of the biological aggressivity of the hypertetraploid breast carcinomas is that $13(27.1 \%)$ patients died of their disease within three years of diagnosis. Therefore, on the basis of our results, it appears that hypertetraploid breast carcinomas are related to clinical and histopathological characteristics associated with unfavourable prognosis. To explain at a molecular level the various behaviours of distinct ploidy subtypes of breast cancer Ferno et al showed that hypertetraploid tumours exhibit the highest proportion of c-erbB-2 amplification and found this subgroup to be associated with aggressive disease evolution. ${ }^{22}$ Similarly, a recent study by Shackney et al suggested that the occurrence of 
hypertetraploid clones is indicative of poor outcome, as well as the phenotypic association of hypertetraploidy, HER-2/neu and ras overexpression in the same breast tumour cells can be predictive for tumour recurrence. ${ }^{44}$

The present study showed that DNA hypertetraploidy in breast cancer is associated with a more aggressive biological behaviour of the neoplasm; therefore, this may be an additional prognostic indicator. In this context, it is of interest that one case in our study had pT1 invasive papillary carcinoma (fig 2), a histological subtype usually devoided of metastatic potential, ${ }^{1}$ that presented uncommon axillary nodal involvement.

In an attempt to explain the biological significance of flow cytometric DNA hypertetraploidy in breast cancer as well as in other tumour types, it can be hypothesised that its common occurrence in association with advanced stages of disease may reflect biomolecular characteristics of the neoplastic progression mechanism through the selection of more aggressive neoplastic clones. ${ }^{45}$ The presence of multiploid clones in 17 of the 51 tumour samples in the present study (fig 3 ) is in favour of the interpretation of such an evolutionary process of acquisition of increasingly abnormal tumour stemlines.

The authors thank Teresa Pereira for her excellent technical assistance.

1 Tavassoli FA. Pathology of the breast. Norwalk: Appleton \& Lange, 1992.

2 Carter CL, Allen C, Henson DE. Relation of tumor size, lymph node status and survival in 24,740 breast cance cases. Cancer 1989;63:181-7.

3 Mansour EG, Ravdin PM, Dressler L. Prognostic factors in early breast carcinoma. Cancer 1994;74:381-400.

4 Wold LE, Ingle JN, Pisansky TM, Johnson RE, Donohue $\mathrm{JH}$. Prognostic factors for patients with carcinoma of the breast. Mayo Clin Proc 1995;70:678-9.

5 Page DL. Prognosis and breast cancer: recognition of lethal and favorable prognostic types. Am f Surg Pathol 1991;15: and favorab 439 .

6 Gasparini G, Pozza F, Harris AL. Evaluating the potential usefulness of new prognostic and predictive indicators in node-negative breast cancer patients. $\mathcal{F}$ Natl Cancer Inst 1993;85:1206-19.

7 Batsakis JG, Sneige N, El-Naggar AK. Flow cytometric (DNA content and S-phase fraction) analysis of breast cancer. Cancer 1993;71:2151-3.

8 Frierson HF. Ploidy analysis and S-phase fraction determination by flow cytometry of invasive adenocarcinomas of the breast. Am $f$ Surg Pathol 1991;15:358-67.

9 Merkel DE, McGuire WL. Ploidy, proliferative activity and prognosis: DNA flow cytometry of solid tumors. Cancer prognosis: DNA flow

10 Hedley DW, Clark GM,Cornelisse CJ, Killander D, Kute T, Merkel D. Consensus review of the clinical utility of DNA cytometry in carcinoma of the breast. Cytometry 1993;14 $482-5$.

11 Cornelisse CJ, van de Velde CJ, Caspers RJ, Moolenaar AJ, Hermans J. DNA ploidy and survival in breast cance patients. Cytometry 1987;8:225-34.

12 Clark GM, Dressler LG, Owens MA, Pounds G, Oldaker T, McGuire WL. Prediction of relapse or survival in patients with node-negative breast cancer by DNA flow cytometry. N Engl f Med 1989;320:627-33.

13 van der Linden JC, Lindeman J, Baak JP, Meijer CJ, Herman CJ. The multivariate prognostic index and nuclear DNA content are independent prognostic factors in primary breast cancer patients. Cytometry 1989;10:56-61.

14 Camplejohn RS, Ash CM, Gillett CE, Raikundalia B, Barnes DM, Gregory WM, et al. The prognostic significance of DNA flow cytometry in breast cancer: results from 881 patients treated in a single centre. Brf Cancer 1995;71: 140-5.

15 Dowle CS, Owainati A, Robins A, Burns K, Ellis IO, Elston $\mathrm{CW}$, et al. Prognostic significance of the DNA content of human breast cancer. Br f Surg 1987;74:133-6.

16 Muss HB, Kute TE, Case LD, Smith LR, Booher C, Long $\mathrm{R}$, et al. The relation of flow cytometry to clinical and biologic characteristics in women with node negative primary breast cancer. Cancer 1989;64:1894-900.

17 Keyhani-Rofagha S, O'Toole RV, Farrar WB, SickleSantanello B, DeCenzo J, Young D. Is DNA ploidy an independent prognostic indicator in infiltrative nodenegative breast adenocarcinoma? Cancer 1990;65:1577-82 18 Witzig TE, Ingle JN, Cha SS, Schaid DJ, Tabery RL, Wold LE, et al. DNA ploidy and the percentage of cells in S-phase as prognostic factors for women with lymph node negative breast cancer. Cancer 1994;74:1752-61.

19 Kallioniemi OP, Blanco G, Alavaikko M, Hietanen T, Mattila J, Lauslahti $\mathrm{K}$, et al. Improving the prognostic value of DNA flow cytometry in breast cancer by combining DNA index and S-phase fraction: a proposed classification of DNA histograms in breast cancer. Cancer 1988;62:218390.

20 Joensuu H, Toikkanen S, Klemi PJ. DNA index and S-phase fraction and their combination as prognostic factors in operable ductal breast carcinoma. Cancer 1990;66:331-40.

21 Beerman $H$, Kluin $M$, Hermans J, van de Velde CJH, Cor nelisse CJ. Prognostic significance of DNA-ploidy in a series of 690 primary breast cancer patients. Int $\mathcal{f}$ Cancer 1990;45:34-9.

22 Ferno M, Baldetorp B, Borg A, Olsson H, Sigurdsson H, Killander D. Flow cytometric DNA index and S-phase fraction in breast cancer in relation to other prognostic variables and to clinical outcome. Acta Oncol 1992;31:15765.

23 Beahrs OH, Henson DE, Hutter RVP, Kennedy BJ, eds. Manual for staging of cancer. 4th ed. Philadelphia: JB Lippincott, 1992

24 Azzopardi JG, Chepick OF, Hartmann WH, Jafarey NA, Llombart-Bosch A, Ozzello L, et al. The World Health Organization histological typing of breast tumors, 2nd ed Am $\mathcal{F}$ Clin Pathol 1982;78:806-16.

25 Elston CW, Ellis IO. Pathological prognostic factors in breast cancer. I. The value of histological grade in breast cancer: experience from a large study with long-term follow-up. Histopathology 1991;19:403-10

26 Gray W. Diagnostic cytopathology. New York: Churchill Livingstone Inc, 1995.

27 Greene G, Press MF. Immunochemical evaluation of estrogen receptor and progesterone receptor in breast cancer. In: Ceriani R, ed. Immunological approaches to the diagnosi and therapy of breast cancer. New York: Plenum Publishing, 1987:119-35.

28 Hsu SM, Raine L, Fanger H. The use of antiavidin antibody and avidin-biotin-peroxidase complex in immunoperoxidase technics. Am $\mathcal{F}$ Clin Pathol 1981;75:816-21.

29 Cattoretti G, Becker M, Key G, Duchrow M, Schluter C, Galle J, et al. Monoclonal antibodies against recombinant parts of the Ki-67 antigen (MIB1 and MIB3) detect proliferating cells in microwave-processed formalin-fixed paraferating cells in microwave-processed form

30 Deitch AD, Law H, White RD. A stable propidium iodide staining procedure for flow cytometry. $\mathcal{f}$ Histochem Cytochem 1982;30:967-72.

31 Vindelov LL, Christensson IJ, Nissen NI. Standardization of high-resolution flow cytometric DNA analyses by simultaneous use of chicken and trout red blood cells as internal reference standards. Cytometry 1983;3:328-31.

32 Dean PN, Jett JH. Mathematical analysis of DNA distributions derived from flow microfluorometry. $\mathcal{F}$ Cell Biol 1974; 60:523-7.

33 Hiddemann W, Schumann J, Andreeff M, Barlogie B, Herman CJ, Leif RC, et al. Convention on nomenclature for DNA cytometry. Cytometry 1984;5:445-6.

34 Shackney SE, Singh SG, Yakulis R, Smith CA, Pollice AA, Petruolo S, et al. Aneuploidy in breast cancer: a fluorescence in situ hybridization study. Cytometry 1995; 22:282-91.

35 Dressler LG, Seamer LC, Owens MA, Clark GM, McGuire WL. DNA flow cytometry and prognostic factors in 1331 frozen breast cancer specimens. Cancer 1988;61:420-7.

36 Fisher ER, Anderson S, Redmond C, Fisher B. Pathologic findings from the National Surgical Adjuvant Breast Project Protocol B-06. 10-year pathologic and clinical project Protocol B-06. 10-year pathologic and clin

37 Toikkanen S, Joensuu H, Klemi PJ. Nuclear DNA content as a prognostic factor in T1-2 No breast cancer. Am f Clin Pathol 1990;93:471-9.

38 Hedley DW, Rugg CA, Gelber RD. Association of DNA index and S-phase fraction with prognosis of node-positive early breast cancer. Cancer Res 1987;47:4729-35.

39 O'Reilly SM, Richards MA. Is DNA flow cytometry a useful investigation in breast cancer? Eur 7 Cancer 1992;28 504-7.

40 Sigurdsson H, Baldetorp B, Borg A, Dalberg M, Ferno M, Killander $\mathrm{D}$, et al. Indicators of prognosis in node-negative breast cancer. $N$ Engl f Med 1990;322:1045-53.

41 Ottesen GL, Christensen IJ, Larsen JK, Kerndrup GB, Hansen B, Andersen JA. DNA aneuploidy in early breast cancer. Br f Cancer 1995;72:832-9.

42 Olszewski W, Darzynkiewicz Z, Rosen PP, Schwartz MK Melamed M. Flow cytometry of breast carcinoma. I. Relation of DNA ploidy level to histology and estrogen receptor. Cancer 1981;48:980-4.

43 Moran R, Black M, Alpert L. Correlation of cell-cycle kinetics, hormone receptors, histopathology, and nodal status in human breast cancer. Cancer 1984;54:1586-90.

44 Shackney SE, Smith CA, Pollice AA, Janocko LE, Singh SG, Groft DW, et al. Preferred genetic evolutionary sequences in human breast cancer: a case study. Cytometry 1995;21:6-13.

45 Nowell PC. The clonal evolution of tumor cell populations. Acquired genetic lability permits stepwise selection of variant sublines and underlies tumor progression. Science 1976;194:23-8. 